\title{
The Academic Open Access E-Journal: Platform and Portal
}

\author{
Alex Koohang \\ University of Wisconsin - \\ Milwaukee \\ Milwaukee, WI, USA
}

koohang@uwm.edu

\author{
Keith Harman \\ International Journal of \\ Doctoral Studies \\ Prescott, AZ USA
}

\begin{abstract}
This paper demonstrates that advanced technologies and the increasing acceptance of academic open access e-journals offer an opportunity to reconsider their form and function as a medium to enhance scholarly communication. The academic open access e-journal is envisioned as a platform and a portal within the context of an open source community including a format and functions that enable it to achieve that objective. A working model for academic open access ejournals is presented. This model is intended for open source communities involved in designing, developing, and/or improving open access academic e-journals.
\end{abstract}

Keywords: Academic open access e-journals, scholarly communication, open access platforms, open access portals, open source communities

\section{Introduction}

The first purpose of this paper is to explore how technologies and the growing acceptance of academic open access e-journals offer an opportunity to rethink their form and function. The second purpose of this paper is to describe a model that contains essentials elements inherent to the success of academic open access e-journals.

The paper's introductory remarks confirm two key points or working assumptions that underlie the purposes of the paper. Firstly, it is shown that academic open access e-journals are gaining widespread acceptance in most if not all disciplines and fields of study. Secondly, it is shown that conceptualizing academic open access e-journals as "platforms" and "portals" represents a paradigm shift with many potential benefits for theory and praxis in most, if not all, disciplines and fields of study.

The discussion then shifts to describing a working model aimed toward the open source communities involved in designing, developing, and/or improving open access academic e-journals.

Material published as part of this publication, either on-line or in print, is copyrighted by the Informing Science Institute. Permission to make digital or paper copy of part or all of these works for personal or classroom use is granted without fee provided that the copies are not made or distributed for profit or commercial advantage AND that copies 1) bear this notice in full and 2) give the full citation on the first page. It is permissible to abstract these works so long as credit is given. To copy in all other cases or to republish or to post on a server or to redistribute to lists requires specific permission and payment of a fee. Contact Publisher@InformingScience.org to request redistribution permission.
Conclusions and recommendations for future research round out the paper.

\section{The Rise of Academic Open Access E-Journals}

The advance of scholarly communication has generally coincided with advances in communications technology 
and infrastructure (Schaefer, 1994). But Kronick (1976) cautions avoidance of a simplistic causeand-effect perspective because the rise of scientific journals in Europe was the result of a complex set of forces beyond advances in communications technology (e.g. the printing press) and distribution systems (e.g. regular mail service). The scientific journal arose in the midst of the scientific revolution as scientific inquiry became more structured and the presentation and discussion of its results became increasingly public (Bazeman, 1988; Kronick, 1976, Sarton, 1957). The process of editorial peer-review and regularly published journals ("periodicals") represent the culmination of a historical process involving scholars, publishers, institutions of higher education, government, philanthropic organizations, and professional associations and learned societies (Burnham, 1990; Eamon, 1990; Hagstrom, 1965). The academic open access e-journal represents yet another step in that historical process.

It is important to define the term "academic open access e-journal" because it is often used interchangeably with terms like "online journal" "academic e-journal" and "electronic journal." An academic open access e-journal is a peer-reviewed, edited, scholarly journal that is published online. It uses the Internet and web-based technologies to collect manuscripts for review, disseminate them to reviewers, collect manuscripts that have been reviewed, and notify authors of the results of peer review (c.f. Ashling, 2005; Baudoin, 2003; Hovav \& Gray, 2004). In addition, an academic open access e-journal has a specific Web presence that contains digital peerreviewed, edited, scholarly manuscripts that are made available online free of charge and often free of most copyright and licensing restrictions.

The academic open access e-journal as defined herein differs significantly from an "electronic journal" created by the conversion of a "paper journal" to digital form and the subsequent archival of its contents in an electronic database, in a portable storage device such as a $\mathrm{CD}$, on the Internet, or some combination of those three.

For the purpose of this paper, the definition of academic open access e-journals is based upon Budapest Open Access Initiative, International Federation Library Associations, Bethesda Statement on Open Access, and Berlin Declaration on Open Access. These merit a brief overview.

The Budapest Open Access Initiative (http://www.soros.org/openaccess/read.shtml) states that

The literature that should be freely accessible online is that which scholars give to the world without expectation of payment... open access to this literature, [means] its free availability on the public internet, permitting any users to read, download, copy, distribute, print, search, or link to the full texts of these articles, crawl them for indexing, pass them as data to software, or use them for any other lawful purpose, without financial, legal, or technical barriers other than those inseparable from gaining access to the internet itself. The only constraint on reproduction and distribution, and the only role for copyright in this domain, should be to give authors control over the integrity of their work and the right to be properly acknowledged and cited. (paragraph 3 )

This initiative is possible through self-archiving and open access journals.

Bethesda Statement on Open Access (http://www.earlham.edu/ ppeters/fos/bethesda.htm ), International Federation Library Associations (http://www.ifla.org/V/cdoc/open-access04.html ), and Berlin Declaration on Open Access (http://www.zim.mpg.de/openaccess-berlin/berlindeclaration.html ) collectively state that "open access is a property of individual works, not necessarily journals or publishers" and that open access must abide by two conditions. They are as follows:

1. The author(s) and copyright holder(s) grant(s) to all users a free, irrevocable, worldwide, perpetual right of access to, and a license to copy, use, distribute, transmit and display the work publicly and to make and distribute derivative works, in any digital medium for any 
responsible purpose, subject to proper attribution of authorship (Community standards, rather than copyright law, will continue to provide the mechanism for enforcement of proper attribution and responsible use of the published work, as they do now), as well as the right to make small numbers of printed copies for their personal use.

2. A complete version of the work and all supplemental materials, including a copy of the permission as stated above, in a suitable standard electronic format is deposited immediately upon initial publication in at least one online repository that is supported by an academic institution, scholarly society, government agency, or other well-established organization that seeks to enable open access, unrestricted distribution, interoperability, and long-term archiving.

The production of open access e-journals is not free. Those publishing open access e-journals bear the expenses that mostly include time of editors and reviewers, server space to publish the manuscripts, and any costs borne in producing and distributing the publication in "hard copy" "bound" format.

Obviously, academic open access e-journals would not exist without the technology that enables them to exist. However as is the case with scientific and technical journals in general, academic open access e-journals have been created as a result of the changing nature of scientific inquiry and scholarly communication. For example, three key forces or factors that promote or encourage the rise of academic open access e-journals include: 1) scholars' impatience with the long timelag between submission of a manuscript and its eventual publication, 2) scholars' desire to address perceived shortcomings of the process of peer-review, and 3) the rise of "team science" and multidisciplinary and transdisciplinary research "genres."

The time-lag between submission of articles and their publication is critical for researchers in fields in which knowledge is rapidly changing and credit for "discovery" may rest on the relative timeliness with which a research study is published (c.f. Brown, 2001; Hanes, 2001; Harnad, 1990, 1995, 1997, 2000 as cited in Mizzaro, 2003). It is also critical for faculty who are seeking tenure and promotion and who thus have a limited period of time to identify a "research agenda" and subsequently create a track record of publications (c.f. Denning, 1997; Swanson, 2004). In contrast to traditional journals in which acceptance of a paper and its actual publication may range from several months to one to three years, academic open access e-journals offer better options. They follow a "rolling" publication sequence in which publication occurs online once a paper is accepted. "Hard copy" or "print copy" of the publication is also available: 1) for a fee on demand or 2) for a fee on a periodic or predetermined basis (e.g. quarterly or annually).

Scholars' dissatisfaction with the peer-review process in scholarly publications is welldocumented (c.f. Hayes, 2002; "Methodical progress," 1997; Monastersky, 2005; Starbuck, 2005). Scholars' dissatisfaction is well-founded, given results of studies on the peer-review process. Weller (2001) reports low reliability of peer reviews. Similar findings are reported by Fenn (1997). Weller (2001) has conducted an extensive analysis of studies on peer-review and reports great divergence in the reliability of peer-reviews. Frey (2003) reports similar findings as regards the discipline of economics. These later studies confirm findings reported in an earlier study (Stuart, 1988) that reviewers rely upon heuristics as opposed to any formal evaluation process or procedure.

Beyond their dissatisfaction with the peer-review process, scholars are increasingly calling for peer-review to be more than a method to screen research worthy of publication. Scholars want peer-review to move from an exercise in summative evaluation to a process that involves open (public) development of a research study within the purview of a community of peers (c.f. Ashling, 2005; Dagani, 1995; Faxon Institute, 1991, as cited in Schaeffer, 1994; La Manna \& Young, 
2002; Mizzaro, 2003; Oliver, 1995 as cited in Peters, 1995; Stodosky, 1995). One scholar (Bachrach, 2005, paragraph 32) argues:

It is clear that electronic publication can serve the scientific community in new ways. The key to publication is information distribution. Electronic publication facilitates this in many ways, some quite novel. Electronic distribution is likely to be less expensive than print. Access by scientists around the world is likely to be much greater and easier. Documents can be made available in less time. Information content is boosted via the electronic medium, allowing for publication of audio, video, large data sets, and interactive tools. The tyranny of page limits becomes obsolete, and while conciseness will remain next to godliness, the advantage of allowing all quality work to be accepted surely outweighs the disadvantage of some verbose contributions. Peer review can be made more inclusive and can empower the community as a whole.

The future of electronic publication holds out hope for a true information revolution. Consider this statement from the UCLA Office of Scholarly Communication (2005, paragraph 3):

Internet technologies are creating new opportunities: While technology has not substantially decreased the cost of producing and reviewing scholarship, it has created efficiencies in those processes. Further, technology allows much greater dissemination at nearly zero marginal cost for additional readers. Technology also enables quicker publication, access to supplementary or source materials, new forms of commentary and dialogue, and new ways to discover and aggregate scholarly resources.

Alternatives to traditional publishing are being thoroughly tested: Several models for disseminating scholarship have emerged and are being deployed. The primary advantage of alternative forms of publishing is that they provide unrestricted (free) access to all potential readers, as compared to traditional subscription or purchase-based publications.

Most alternative forms of publishing also:

- Include peer-review or other quality control.

- Are available quickly or immediately after creation.

- Are managed for long-term availability.

- Are discoverable through traditional indexes or new, community-built services" (UCLA, 2005, paragraphs 3-4).

The rise of academic open access e-journals is one aspect of a growing movement to rethink academic journals and the process of scholarly communication. For example, the Directory of Open Access Journals (DOAJ, 2005) contains over 1,680 journals and 76,416 articles. Lamp (2004) provides links to an additional set of academic open access e-journals. Also, open access peer-reviewed journals have impact factors and citation rates equal to traditional peer-reviewed journals (ISI Thomson 2004, as cited in UCLA, 2005). Vaughn (2003) notes that online "equivalent-print" journals are significantly impacting use patterns in chemistry journals. Brooks (1999) has deemed these trends as part of "postmodern information science." Brooks states:

In the postmodern information era, scholars will be publishers, academic review will be instantaneous with publication, and universities will seek to maximize their assets and

vend a product. These may be the last days of the paper-based scholarly journal. (p. 1030)

While it is certainly premature to herald the demise of the paper-based journal, it is clear that academic open access e-journals will at least play a complementary and important role in scholarly communication. The promise of the academic open access e-journal is tempered by the realities 
of available technology and critics' concerns (c.f. Ball, 2004; Harter, 1998; Kling \& Covi, 1995; Odlyzko, 1995).

As is the case with any innovation, there will always be those who refuse to accept academic open access e-journals as a legitimate venue for scholarly communication. For those who hold a different perspective the format and function of academic open access e-journals merits discussion. Such discussion is not limited to mere speculation. Available technologies offer a set of tools to turn academic open access e-journals into ideal "platforms" and "portals.

\section{Academic Open Access E-Journals as Platforms and Portals}

The Internet technologies and Web-enabled tools as well as the open source communities play critical roles in designing and developing academic open access e-journals. Managing content, with its intelligent delivery and presentation, is critical to the success of academic open access ejournals. The system of choice must reduce publishing cycle; improve efficiency; enhance communication; improve interaction; and guarantee distinct and excellent user experience.

In this section, we describe a working model for academic open access e-journals. The model contains three essential parts. Each part possesses unique functionalities inherent to success of academic open access e-journals. These parts are: the communication platform, the content management platform, and the portal.

We view this model as the rule and not the exception. This model is a common - essential to the success of academic open access e-journals. It is aimed toward the open source communities involved in designing, developing, and/or improving open access e-journals. Open access e-journals represent academe's response to the need for greater and swifter accessibility to research findings that enhance the flow of scholarly communication. Open access e-journals conceptually fit within the paradigm of the open source community.

Mental models or conceptual paradigms are essential but they must ultimately be expressed in practical or operational terms. A number of the model's functionalities apply to current open source projects that have developed open access e-journal systems such as Open Journal System (http://pkp.sfu.ca/ojs/ ), eFirst (http://www.openly.com/efirst/), and HyperJournal (http://www.hjournal.org/). These systems have their strengths and weaknesses. The evaluations of these systems are beyond the scope of this paper. Readers interested in learning more about the functionalities of these systems should visit the following Web sites:

- http://www.pkp.ubc.ca/OJS_Sheet.h tml (Open Journal System)

- http://www.openly.com/efirst/ (eFirst)

- http://www.hjournal.org/overview (HyperJournal)

Figure 1 depicts a working model for academic open access e-journals.

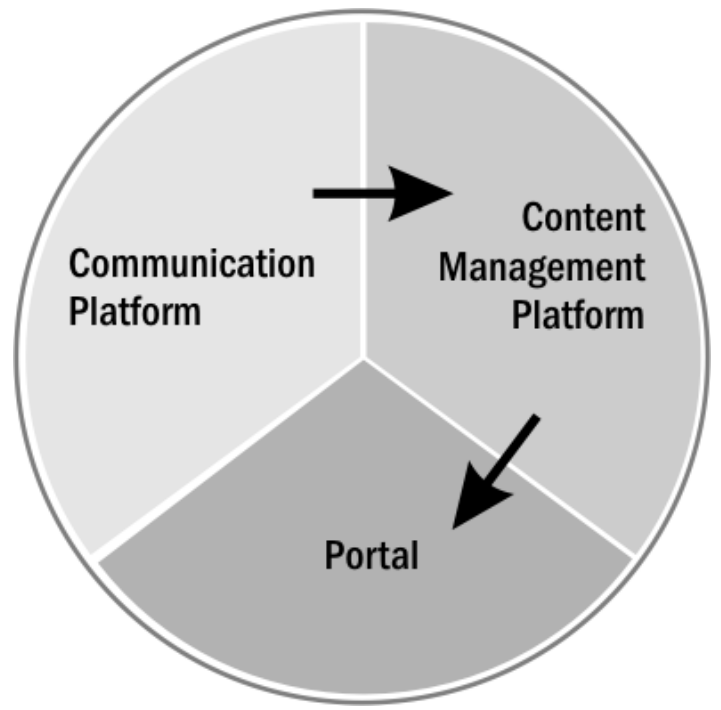

Figure 1: A Model for Open Access EJournals 
It synergizes elements of technologies for maximum benefit from academic open access ejournals. The system contains three essential parts critical to success of open access e-journals. They are communication platform, content management platform, and open access portal. Each essential part in the model has several major components. All components in the three parts work together and complement one another. Once these parts are put together, the process of communication, content/manuscript management, and open access to the academic peer-reviewed manuscripts can be substantially improved. In the next section, the critical components of each part are discussed.

\section{Communication Platform}

The communication platform is the primary system that links the author to the editor. The main tasks/components in this system must include:

- Author Submission Task - Author electronically submits his/her manuscript for possible review and possible publication in the journal

- Initial Editorial Task - The editor screens the manuscript to determine its suitability for possible publication in the journal. If the manuscript is determined suitable for possible publication, the editor assigns it to 2 or more appropriate reviewers who are comfortable reviewing the paper. The system must allow reviewers to choose topics that match their expertise and knowledge so the editor can choose the appropriate reviewers or so it can be done automatically.

- Reviewers Task - The reviewers are asked to review the manuscript and make recommendation regarding acceptance or rejection of the manuscript. If the paper is accepted, the reviewer is asked to provide constructive feedback on how to improve the paper. If the paper is rejected, the reviewer is also asked to provide constructive feedback on how the paper can be improved.

- Second Editorial Task - Once the reviews are completed, the editor communicates with the author and provides a detailed feedback regarding the decision for publication. The editor will do the same for papers that are rejected and in most cases another outlet is suggested to the author.

- Revising Task - The author revises the manuscript and re-uploads the manuscript into the system.

- Third Editorial Task - The editor edits the paper, communicates with the author and prepares the paper for the Content Management Platform.

\section{Content Management Platform}

The Content Management Platform is responsible for content formatting and publication. During this process the ideal platform must have the following components:

- Web Authoring tool - User-friendly web authoring tool that allows template creation and requires no knowledge of XML, HTML, etc. coding.

- Automatic posting of links to articles by extracting required information (i.e., title, author, abstract, keywords)

- XML formatted metadata repository - The open and platform-independent XML formatted repository allows true interoperability among many platforms. 
- Built-in application-independent interoperability framework for marking up manuscripts for harvesting. Normally this will be supported by a protocol. The most common protocol for this purpose is Open Archives Protocol Initiative for Metadata Harvesting (OAI-PMH - http://www.openarchives.org/OAI/openarchivesprotocol.html ). The OAI-PMI supports interoperability standards intended for efficient dissemination of manuscripts. The harvester acts as a metadata indexing system for creating searchable index of metadata from the repository.

- Converting/integrating raw form of the manuscript (XML) into HTML and/or PDF.

\section{Open Access Portal}

The true value of the academic open access e-journals becomes apparent in the portal part of the system. The manuscripts are made available in open access portal where they can be accessed free of charge. The furthering of research within the community of scholars depends on the sound presentation of content/manuscripts and the value-added tools present in the portal. This portal is in direct link with the XML formatted metadata repository and must completely be browserbased. The portal must be accessed in all major browsers. It must also allow the use of PDA technologies to access the portal. The major components of this part are as follows:

- Built-in index - The portal provides a powerful search engine that indexes the manuscripts for searching and finding. It must support advanced querying.

- Data modeling and/or replication of raw data used in manuscripts - The portal makes available the raw data of manuscripts to scholars for data modeling and future replication of the study.

- Text mining - The portal must allow for text mining of the manuscripts. Text mining allows authors to discover hidden facts that may be useful for expanding the knowledge. According to Hearst (2002, paragraph 1), text mining is "the discovery by computer of new, previously unknown information, by automatically extracting information from different written resources. A key element is the linking of the extracted information together to form new facts or new hypotheses to be explored further by more conventional means of experimentation."

- Discussion board - Readers should be able to use the discussion forum to post their opinions about the articles they read. The discussion forum becomes a learning community that promotes further research among scholars. The authors of published manuscripts are automatically a part of this learning community. In the learning community scholars may find mutual interest in topics and collaborate on future research.

- Collaboration tool - The collaboration tool, also known as groupware, allows authors to collaborate on research that interests them mutually. It can organize content in context and give meaning to information (which then becomes knowledge) among the research communities of common interest to further enhance and improve research.

- The Rich Site Summary (RSS) - The Rich Site Summary (RSS) is an XML format used to syndicate manuscripts. This acts as an intelligent agent that allows other portals to publish certain information about the manuscripts, i.e., author's name, title, source with date and volume number, and in some cases the manuscript's abstract.

\section{User Interface and Scalability}

Usability is fundamental to the proposed conceptual system for academic open access e-journals. Usability attributes are the result of a usable system. These attributes are objective: effectiveness, 
learnability, flexibility, understandability, memorability, and reliability; and subjective: positive attitude, user satisfaction, and product/system attractiveness (International Organization for Standardization [ISO] 9241-11, 1998; ISO/International Electrotechnical Commission [IEC] 9126, 1991; Nielsen, 1993; Shackle, 1991).

Usability properties are elements that accomplish the usability attributes. They are essential to user interface design and achieve usability of a system (Dumas \& Redish, 1993; ISO 9241-11; ISO/IEC 9126; Nielsen 1993; Rosenbaum, 1989; Rubin, 1994; Shackel 1991).

Based on the review of literature, Koohang (2004) identified a number of usability properties inherent to the successful use of a system. They are simplicity, comfort, user-friendliness, control, navigability, load/access time, readability, adequacy/task match, link visibility, high/readable color contrast, appropriate font type/size, well organized, visual presentation, recognition, information relevancy, right to the point information, consistency, feedback, and direction. These usability properties are fundamental to user interface design and must be built in the open access academic e-journals.

The academic open access e-journal must achieve high scalability. Scalability is the ability of the system to easily adapt to the existing needs. The adaptability could be scaling the hardware and/or software to safeguard larger volumes of manuscripts or being able to accept/allow increased users to the portal without any problems. Scalability of the proposed system is about being able to modify the system to meet the current and future needs of the academic open access e-journals.

\section{Conclusion}

Ironically, what we suggest is the use of existing and/or improved technologies to "turn back the clock" to a time when scholarly communication was as fluid, personal, interactive, and immediate as possible (c.f. Ruegg, 1996, pp. 16-17, 27). History indicates that scholars will seek alternative methods of communication and alternative organizational structures when they perceive that existing media and existing structures no longer provide the support scholars need to most effectively engage in scientific inquiry and to communicate their findings. Pedersen (1996, pp. 470474) for example recounts that during the $16^{\text {th }}$ and $17^{\text {th }}$ centuries many of Europe's most gifted scientists made an exodus from the universities to the first institutes for scientific research. Similarly, Ruegg (1992, pp. 465-467) argues that book-publishing and foundations became the "ally" of humanism and augmented its initial wide-scale diffusion throughout Europe during the late $15^{\text {th }}$ Century.

The academic open access e-journal is yet another manifestation of that historic process. The academic open access e-journal is a response to scholars' needs; needs that at their core have not changed in nearly a millennium. But there is a qualitative difference. When the open source communities choose to synergize existing and/or new technologies with sound design and functionalities in a system, the academic open access e-journal is capable of enhancing scholarly communication on a global scale at a speed and "richness" never anticipated.

Naturally, the academic open access e-journal is merely a tool. It is no substitute for the brilliant mind driven by a passion for scientific inquiry and it will never eliminate the biases and foibles of the "real" people who also happen to be scholars. But the academic open access e-journal does provide us the means to do something perhaps as important as conducting inquiry and disseminating the results. The academic open access e-journal provides a historic opportunity to observe the scientific process as it unfolds on a scale and timing never achieved before.

This may be its most important potential. In turn, this prospect raises important questions: "If science is a craft or an art, how can we use the academic open access e-journal as fertile ground to study the process of scientific inquiry itself?" "Will studying how we perform this art or craft en- 
able us to improve our performance?" "Will it enable us to reconsider fundamental tenets of scholarship and identify those tenets that retain value and those that may no longer be relevant?" "Will the academic open access e-journal become the primary fulcrum around which "post modern science' can be explored?" "Is scientific inquiry and scholarly communication a fully conscious process and if not what elements of its unconscious aspects merit scrutiny?"

Those are interesting questions and by no means even a fledgling start towards an exhaustive list of critical questions raised by the promise of the academic open access e-journal. Yet two things are certain. Firstly, the academic open access e-journal promises to allow scholars to enhance the speed and diffusion of their work. Secondly, the academic open access e-journal as we envision it offers a transparency that permits scholars to obtain a fuller glimpse of the scientific process in "real time" on an unprecedented scale. These benefits alone should motivate the open source communities to identify and exploit the technological synergies that can enhance scientific inquiry, scholarly communication, and the life of the mind.

\section{References}

Ashling, J. (2005). The web and after: The future of scholarly e-publishing. Information Today, 22(6), 3334.

Bachrach, S. (2005). Scientific journals of the future. Retrieved August 18, 2005, from http://www.amacad.org/publications/trans4.aspx

Ball, D. (2004). What's the "big deal," and why is it a bad deal for universities? Interlending \& Document Supply, 32(2), 117-125.

Baudoin, P. (2003). Uppity bits: Coming to terms with archiving dynamic electronic journals. Serials Librarian, 43(4), 63-72.

Bazeman, C. (1988). Shaping written knowledge: The genre and activity of the experimental article in science. Madison, WI: University of Wisconsin Press.

Brooks, T. A. (1999). Postmodern information science and its "journal." Journal of the American Society for Information Science, 50(11), 1030-1031.

Brown, C. (2001). The e-volution of preprints in the scholarly communication of physicists and astronomers. Journal of the American Society for Information Science and Technology, 52, 187-200.

Burnham, J. (1990). The evolution of editorial peer review. Journal of the American Medical Association 263 (March 9), 1323-29.

Dagani, R. (1995). New journal forgoes traditional peer review. Chemical and Engineering News, 73(21), 26-27.

Denning, P.J. (1997). A new social contract for research. Association for Computing Machinery. Communications of the ACM, 40(2), 132-134.

DOAJ. (2005). Directory of Open Access Journals. Retrieved August 18, 2005, from http://www.doaj.org/

Dumas, J. \& Redish, J. (1993). A Practical Guide to Usability Testing. Norwood, NJ: Ablex

Eamon, W. (1990). From the secrets of nature to public knowledge. In D. C. Lindberg \& R. S. Westman (Eds), Reappraisals of the Scientific Revolution. Cambridge: Cambridge University Press.

Fenn, P. (1997). Rigour in research and peer review. Construction Management and Economics, 15(4), 383-386.

Frey, B. S. (2003). Publishing as prostitution? Choosing between one's own ideas and academic success. Public Choice, 116(1-2), 205-223.

Hagstrom, W. (1965). The scientific community. New York: Basic Books. 
Hanes, P. J. (2001). IT interview bepress.com introduces innovative scholarly publishing model. Information Today, 18(3), 1, 56.

Harter, S. P. (1998). Scholarly communication and electronic journals: An impact study. Journal of the American Society for Information Science, 49, 507-516.

Hayes, J. A. (2002). The myth of objectivism in counseling psychology research: Reviewing reviewers' reviews. ProQuest Dissertations and Theses, 63(5), AAT 3051645.

Hearst, M. (2003). What is text mining? Retrieved October 18, 2005 from http://www.sims.berkeley.edu/ hearst/text-mining.html

Hovav, A. \& Gray, P. (2004). Managing academic open access e-journals. Communications of the ACM, 47(4), 79-83.

ISO 9241-11 (1998). Ergonomic requirements for office work with visual display terminals(VDT)s - Part 11 Guidance on usability. Geneva, Switzerland: ISO.

ISO/IEC 9126 (1991). Software product evaluation - Quality characteristics and guidelines for their use. Geneva, Switzerland: ISO.

Kling, R. \& Covi, L. (1995). Electronic journals and legitimate media in scholarly communication. The Information Society, 11, 261-271.

Koohang, A. (2004). A study of users' perceptions toward e-learning courseware usability. International Journal on E-Learning.

Kronick, D.A. (1976). A History of scientific and technical periodicals: The origins and development of the scientific and technical press. Metuchen, N.J.: Scarecrow.

La Manna, M.L. \& Young, J. The electronic society for social scientists: from journals as documents to journals as knowledge exchanges. Interlending and Document Supply, 30(4), 178-182.

Lamp, J. W. (2004). Index of Information Systems Journals. Retrieved August 18, 2006 from http://lamp.infosys.deakin.edu.au/journals/

Methodical progress. (1997). The Economist, 344(8036), 89-90.

Mizzaro, S. (2003). Quality control in scholarly publishing: A new proposal. Journal of the American Society for Information Science and Technology, 54(11), 989-1005.

Nielsen, J. (1993). Usability Engineering. San Diego, CA: Academic press.

Monastersky, R. (2005). The number that's devouring science. The Chronicle of Higher Education, 52(8), A12.

Odlyzko, A. M. (1995). Tragic loss or good riddance? The impending demise of traditional scholarly journals. International Journal of Human Computer Studies, 42, 71-122.

Pedersen, O. (1996). Tradition and innovation. In H. D. Ridder-Symoens (Ed.), A history of the university in Europe: Volume II universities in early modern Europe (1500-1800) (pp. 451-488). Cambridge, UK: Cambridge University Press.

Peters, J. (1995). The Hundred Years' War started today: An exploration of electronic peer review. Internet Research, 5(4), 3.

Rosenbaum, S. (1989). Usability evaluations vs. usability testing: When and why? IEEE Transactions on Professional Communication, 32, 210-16.

Rubin, J. (1994). Handbook of usability testing. New York: John Wiley.

Ruegg, W. (1992). The rise of humanism. In H. D. Ridder-Symoens (Ed.), A history of the university in Europe: Volume I universities in the Middle Ages (pp. 442-446). Cambridge, UK: Cambridge University Press. 
Ruegg, W. (1996). Themes. In H.D. Ridder-Symoens (Ed.), A history of the university in Europe: Volume II universities in early modern Europe (1500-1800) (pp. 3-42). Cambridge, UK: Cambridge University Press.

Sarton, G. (1957). Six wings: Men of science in the Renaissance. Bloomington, IN: Indiana University Press.

Schaefer, A. C. (1994). The future of scientific journals: Lessons from the past. Information Technology and Libraries, 13(4), 239-247.

Shackel, B. (1991). Usability - context, framework, design and evaluation. In B. Shackel \& S. Richardson (Eds.), Human factors for informatics usability (21-38). Cambridge, UK: Cambridge University Press.

Starbuck, W. H. (2005). How much better are the prestigious journals? The statistics of academic publication. Organization Science, (Linthicum), 16(2), 180-202.

Stodosky, D. S. (1995). Consensus journals: Invitational journals based upon peer review. Information Society, 11(4), 247-260.

Stuart, G. (1988). Reviewing the gatekeepers: A survey of referees of library journals. Journal of the American Society for Information Science, 39(6), 400-407.

Swanson, E. P. (2004). Publishing in the majors: A comparison of accounting, finance, management, and marketing. Contemporary Accounting Research Toronto, 21(1), 223-252.

UCLA, Office of Scholarly Communication. (2005). The facts: Alternatives for scholarly communication. Retrieved August 18, 2005 from http://osc.universityofcalifornia.edu/facts/alternatives for sc.html

Vaughn, K.T. L. (2003). Changing use patterns of print journals in the digital age: Impacts of electronic equivalents on print chemistry journal use. Journal of the American Society for Information Science and Technology, 54(12), 1149-1152.

Weller, A.C. (2001). Editorial peer review: Its strengths and weaknesses. Medford, NJ: Information Today ASIS\&T Monograph Series.

\section{Biographies}

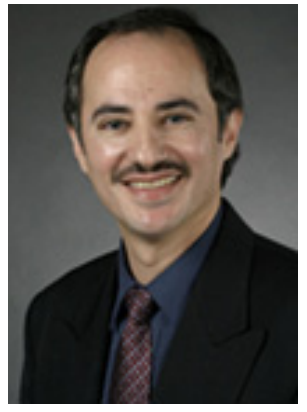

Alex Koohang is a faculty member and the director of undergraduate program in the School of Information Studies at University of Wisconsin Milwaukee, USA. Dr. Koohang has designed, developed, and implemented various traditional, non-traditional, hybrid, and on-line courses/programs. He has been involved in the development of on-line education, having initiated and administered some of the earliest asynchronous learning networks. Dr. Koohang's current research interests are in the areas of learning objects, open education, open access, open source, e-learning, usability, and knowledge management.

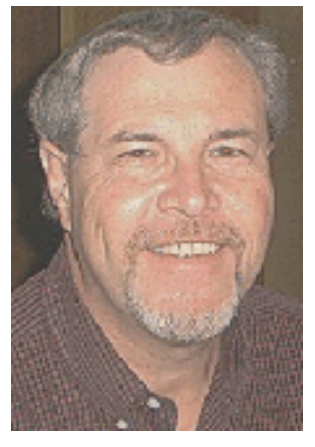

Keith Harman, Ph.D. is an independent consultant for higher education institutions, asset management firms, and non-profit organizations. He is also Editor-in-Chief of the International Journal of Doctoral Studies. His 26 years of experience in academe include stints as a faculty member, department chairperson, dean, and academic research administrator. In addition to three books on information management and strategic planning and over two dozen publications and presentations in journals and proceedings, he has served as a guest lecturer and consultant for Fortune 1000 corporations, major universities, private foundations and government agencies. 